\title{
REDUCTION EXPERIMENT OF FeO- BEARING AMORPHOUS SILICATE: APPLICATION TO ORIGIN OF METALLIC IRON IN GEMS
}

\section{$\operatorname{AUTHOR}(\mathrm{S}):$}

Matsuno, Junya; Tsuchiyama, Akira; Miyake, Akira; Noguchi, Ryo; Ichikawa, Satoshi

\section{CITATION:}

Matsuno, Junya ...[et al]. REDUCTION EXPERIMENT OF FeO-BEARING AMORPHOUS SILICATE: APPLICATION TO ORIGIN OF METALLIC IRON IN GEMS. The Astrophysical Journal 2014, 792(2): 136.

\section{ISSUE DATE:}

2014-09-10

URL:

http://hdl.handle.net/2433/189844

RIGHT:

(C) 2014. The American Astronomical Society. 


\title{
REDUCTION EXPERIMENT OF FeO-BEARING AMORPHOUS SILICATE: APPLICATION TO ORIGIN OF METALLIC IRON IN GEMS
}

\author{
Junya Matsuno $^{1}$, Akira Tsuchiyama ${ }^{1}$, AkIRa MiYaKe $^{1}$, Ryo Noguchi $^{2}$, and Satoshi Ichikawa ${ }^{3}$ \\ ${ }^{1}$ Department of Geology and Mineralogy, Graduate School of Science, Kyoto University, \\ Kitashirakawa-Oiwake, Sakyo-ku, Kyoto 606-8502, Japan; jmatsuno@kueps.kyoto-u.ac.jp \\ ${ }^{2}$ Department of Earth and Space Science, Graduate School of Science, Osaka University, \\ 1-1 Machikaneyama, Toyonaka, Osaka 560-0043, Japan \\ ${ }^{3}$ Institute for Nano-science Design, Osaka University, 1-3 Machikaneyama, Toyonaka, Osaka 560-8531, Japan \\ Received 2013 December 8; accepted 2014 July 24; published 2014 August 26
}

\begin{abstract}
Glass with embedded metal and sulfides (GEMS) are amorphous silicates included in anhydrous interplanetary dust particles (IDPs) and can provide information about material evolution in our early solar system. Several formation processes for GEMS have been proposed so far, but these theories are still being debated. To investigate a possible GEMS origin by reduction of interstellar silicates, we synthesized amorphous silicates with a mean GEMS composition and performed heating experiments in a reducing atmosphere. FeO-bearing amorphous silicates were heated at $923 \mathrm{~K}$ and $973 \mathrm{~K}$ for $3 \mathrm{hr}$, and at $1023 \mathrm{~K}$ for $1-48 \mathrm{hr}$ at ambient pressure in a reducing atmosphere. Fe grains formed at the interface between the silicate and the reducing gas through a reduction. In contrast, TEM observations of natural GEMS show that metallic grains are uniformly embedded in amorphous silicates. Therefore, the present study suggests that metallic inclusions in GEMS could not form as reduction products and that other formation process such as condensation or irradiation are more likely.
\end{abstract}

Key words: circumstellar matter - interplanetary medium - methods: laboratory: solid state

\section{INTRODUCTION}

Cometary materials are one of the most primitive materials in the solar system because they have not suffered from thermal metamorphism and hydrous alternation in their parent bodies, unlike carbonaceous chondrites. Chondritic porous interplanetary dust particles (CP-IDPs, or anhydrous IDPs), which are collected in Earth's stratosphere using airplanes, are considered to have cometary origins (e.g., Bradley \& Brownlee 1986; Flynn 1989). Amorphous silicates in CP-IDPs are dominated by glass with embedded metal and sulfides (GEMS; Bradley 1994a), which amount to as much as half of the mass of some IDPs (Keller \& Messenger 2011). GEMS grains are submicronsized spherical objects (typically $100-500 \mathrm{~nm}$ in diameter) with nanometer-sized (10-50 nm) $\mathrm{Fe}-\mathrm{Ni}$ metal and sulfide grains embedded in an amorphous Mg silicate matrix (e.g., Bradley 1994a, 1994b). GEMS-like materials have also been found in some C-rich Antarctic micrometeorites (Noguchi et al. 2008, 2013; Duprat et al. 2010; Dobrică et al. 2012) and in the matrix of a unique CM meteorite (Leroux et al. 2013). Several formation processes for GEMS have been proposed so far, but these theories are still being debated. They can be grouped into two categories: (1) amorphization products of crystalline silicates in the interstellar medium by sputter deposition of cosmic ray irradiation, similar to space weathering (Bradley \& Dai 2004; Bradley 2013), and (2) condensation products from the residual Si-rich gas after condensation of crystalline Mg silicates, such as forsterite, from the original gas in the primordial solar system (Keller \& Messenger 2011, 2013). Textures similar to those found in natural GEMS, where metallic iron grains are embedded in amorphous silicate spheres reported by a preliminary result of condensation experiments (Matsuno et al. 2014).

The origin of metallic grains in GEMS has also been discussed. Based on laboratory experiments, Davoisne et al. (2006) proposed that metallic grains formed by reduction of $\mathrm{FeO}$ in sili- cates when $\mathrm{FeO}$-bearing interstellar amorphous silicate dust was incorporated into the inner part of the early solar system and experienced some thermal processing. In their experiments, a thin film of $\mathrm{FeO}$-bearing amorphous silicate prepared by sputtering San Carlos olivine $\left(\mathrm{Mg}_{1.8} \mathrm{Fe}_{0.19} \mathrm{Ni}_{0.01} \mathrm{SiO}_{4}\right)$ using an electron beam evaporation technique was heated in a reducing atmosphere at $870 \mathrm{~K}$ and $1020 \mathrm{~K}$ for several hours. Metallic $\mathrm{Fe}-\mathrm{Ni}$ grains formed by reduction of the amorphous silicate, but some details about the metal formation process were not examined, for instance, where in the film did the metal crystallize. In the present paper, we synthesized an amorphous silicate as an analog material of FeO-bearing interstellar silicate dust, and performed heating experiments in a reducing atmosphere to examine the reduction process in detail and to investigate whether or not metallic grains in GEMS formed by reduction of interstellar FeO-bearing silicates.

\section{EXPERIMENTS}

The mean composition of GEMS grains as determined by previous studies (Bradley 1988, 1994a, 1994b; Bradley \& Ireland 1996) was used for the chemical composition of the starting material in the present experiments. The starting material was chosen to contain only divalent $\mathrm{Fe}$ because the author intended to examine the formation process of metallic $\mathrm{Fe}$ from $\mathrm{FeO}$-bearing amorphous silicates by reduction. $\mathrm{MgO}$, $\mathrm{FeO}$, and $\mathrm{SiO}_{2}$ were chosen as the major components of GEMS for simplicity $(\mathrm{MgO}=28 \mathrm{wt} . \%, \mathrm{FeO}=22 \mathrm{wt} . \%$, and $\mathrm{SiO}_{2}=50$ wt.\%). Sulfur was not incorporated into the system because of its experimental difficulty. In addition, the sulfides are considered to form through later sulfurization of metallic iron grains because they are typically located on the surface of GEMS grains (Keller \& Messenger 2011).

$\mathrm{MgO}, \mathrm{FeO}$, and $\mathrm{SiO}_{2}$ powders were well mixed and put into a Fe-saturated $\mathrm{Pt}$ crucible. Chemical reagents of $\mathrm{MgO}$ and $\mathrm{SiO}_{2}$ were used, and the $\mathrm{FeO}$ powder was prepared by decomposition of iron oxalate $\left[\mathrm{Fe}(\mathrm{COO})_{2} \cdot 2 \mathrm{H}_{2} \mathrm{O}\right]$. A melt was 
Table 1

Starting Materials and the Heating Conditions

\begin{tabular}{llrccc}
\hline \hline Run\# & Starting Material & $\begin{array}{c}\text { Temp. } \\
(\mathrm{K})\end{array}$ & $\begin{array}{c}\text { Duration } \\
(\mathrm{hr})\end{array}$ & Phase(s) & Remarks \\
\hline AR1 & SM-A* & 923 & 3 & glass & \\
AR2 & SM-A & 973 & 3 & Opx, Cpx $>$ iron & \\
AR3 & SM-A & 1023 & 1 & Opx, Cpx $>$ iron & \\
AR4 & SM-A & 1023 & 3 & Opx, Cpx $>$ iron & TEM observation ${ }^{\# \#}$ \\
AR5 & SM-A & 1023 & 48 & Opx, Cpx $>$ iron & Opx \\
BR4 & SM-B ${ }^{* *}$ & 1023 & 3 & Opx, Cpx, iron & \\
BR5 & SM-B & 1023 & 48 & Opx, Cpx, iron & \\
CR4 & SM-C $^{* * *}$ & 1023 & 3 & n. d. ${ }^{\# \#}$ & \\
\hline
\end{tabular}

Notes.

* A particle $(\sim 2 \times 2 \times 2 \mathrm{~mm})$ formed at the oxygen fugacity of $\mathrm{IW}+0.5$.

** Powder $(\sim 100 \mu \mathrm{m})$ formed at the oxygen fugacity of IW +0.5 .

*** A particle $(\sim 1 \times 1 \times 1 \mathrm{~mm})$ formed at the oxygen fugacity of IW -0.5

\# The phase identifications were performed with the powder XRD method (Opx: orthopyroxene, Cpx:

clinopyroxene).

\#\# Nano-particles of maghemite were observed.

\#\#\# The amount of this product was so small that the XRD could not be performed.

obtained by heating at $1873 \mathrm{~K}$, well above the liquidus temperature (approximately $1770 \mathrm{~K}$ ), for 10 minutes and was quenched into water. The oxygen fugacity during melting was controlled at $0.5 \log$ units above the iron-wüstite buffer (IW + 0.5) by a flowing $\mathrm{H}_{2}-\mathrm{CO}_{2}$ gas mixture. Some quenched crystals appeared, and the starting materials were carefully selected under an optical microscope to avoid these crystals. The quenched glass was cut into cubes approximately $2 \mathrm{~mm}$ long. This starting material is called SM-A. To evaluate the effect of the volume of starting material, the synthesized glass was ground in an agate mortar and used as an alternative starting material for some experiments (SM-B). The grain size is approximately $1-30 \mu \mathrm{m}$. Another staring material of quenched glass (SM-C) was also made from a melt heated at $1873 \mathrm{~K}$ for 10 minutes under more reducing conditions, at an oxygen fugacity of $0.5 \mathrm{log}$ units below the IW buffer (IW - 0.5) in order to examine the effect of the initial redox state of $\mathrm{Fe}$ in the starting material. The starting material for this type of reduction experiments consisted of pieces of glass approximately $1 \mathrm{~mm}$ in size.

For reduction experiments, all starting materials were put in an open envelope of platinum and heated at $923 \mathrm{~K}, 973 \mathrm{~K}$, and $1023 \mathrm{~K}$ for $1-48 \mathrm{hr}$ in a reducing atmosphere at an oxygen fugacity of $1.5 \mathrm{log}$ units below the IQF (iron-quartz-fayalite) buffer (IQF-1.5; $\left.f_{\mathrm{O}_{2}} \sim 10^{-23} \mathrm{~atm}\right)$ in a one-atmosphere gas mixing furnace using a $\mathrm{H}_{2}-\mathrm{CO}_{2}$ gas flow. The heating temperatures and durations were chosen based on previous experiments (Davoisne et al. 2006). The run conditions are listed in Table 1.

Run products of SM-A were cut into two pieces using a diamond saw. One was used for powder X-ray diffraction analysis (XRD; Geigerflex, Rigaku) at Osaka University and the other was used for texture observation. To prepare powder XRD samples, the run products of SM-A and B were crushed in a tungsten carbide mortar, ground in an agate mortar, and then mounted on a reflection-free quartz sample holder. The samples were exposed to $\mathrm{Cu} \mathrm{K} \alpha$ radiation with an accelerating voltage of $35 \mathrm{kV}$ and a tube current of $25 \mathrm{~mA}$. The surfaces and polished cross sections of run products of SM-A, B, and C were observed with a field emission-scanning electron microscope (FE-SEM; JSM-7001F, JEOL) at Osaka University and analyzed with energy-dispersive X-ray spectroscopy (EDS; Inca, Oxford). An ultrathin section of run product AR5 (heated at $1023 \mathrm{~K}$ for $48 \mathrm{~h}$ ) was made using a focused ion beam (FIB; Quanta 200 3DS, FEI) at Kyoto University and observed under a transmission electron microscope (TEM) equipped with an EDS system at the Institute for Nano-science Design, Osaka University (Tecnai 20 ST, FEI) and Kyoto University (JEM-2100F, JEOL).

\section{RESULTS}

\subsection{Powder XRD analyses}

The XRD pattern of SM-A (Figure 1) shows a halo pattern around a $2 \theta$ angle of $28^{\circ}$ due to amorphous silicate. There is also a small peak at a $2 \theta$ angle of 26.5 that is identified as $\alpha$-quartz, which might be due to contamination from a polishing compound used for cleaning the agate mortar, in which the samples were ground.

Typical XRD patterns of the run products are also shown in Figure 1. The XRD patterns of all run products have peaks identified as orthopyroxene, clinopyroxene, and $\alpha$-iron (metallic Fe) except for AR1 (heated at $923 \mathrm{~K}$ for $3 \mathrm{hr}$ ), which has only a halo pattern due to glass. Orthopyroxene is a stable phase at the heating temperatures (e.g., Huebner 1980). A major difference among the XRD patterns of the crystalline run products is the Fe peak height. The peaks are higher in run products that used powdered starting material (SM-B), such as BR5 (1023 K for $48 \mathrm{hr}$ ) and BR4 (1023 K for $3 \mathrm{hr}$ ), than those using blocky starting materials (SM-A; Figure 1). This suggests that the reduction reaction of $\mathrm{FeO}$ in the glass with the surrounding gas occurred mainly on the glass surface. The $\mathrm{Mg \#}[\mathrm{Mg} /(\mathrm{Mg}+$ $\mathrm{Fe})$ ] of pyroxene in the run products is $0.4-0.5$ based on the $d$-spacing. This value is smaller than that of the starting material $(\mathrm{Mg \#}=0.59)$, suggesting that approximately $10 \%$ or less of the Fe was reduced to form metallic iron. The amount of sample material in CR4 was too small for XRD analysis.

\subsection{SEM Observation}

Back-scattered electron (BSE) images of run product surfaces and cross-sectional images are shown in Figures 2 and 3, respectively. There are many cracks and ridges with some bright particles approximately $1 \mu \mathrm{m}$ or smaller in size. The ridges form 
The Astrophysical Journal, 792:136 (8pp), 2014 September 10

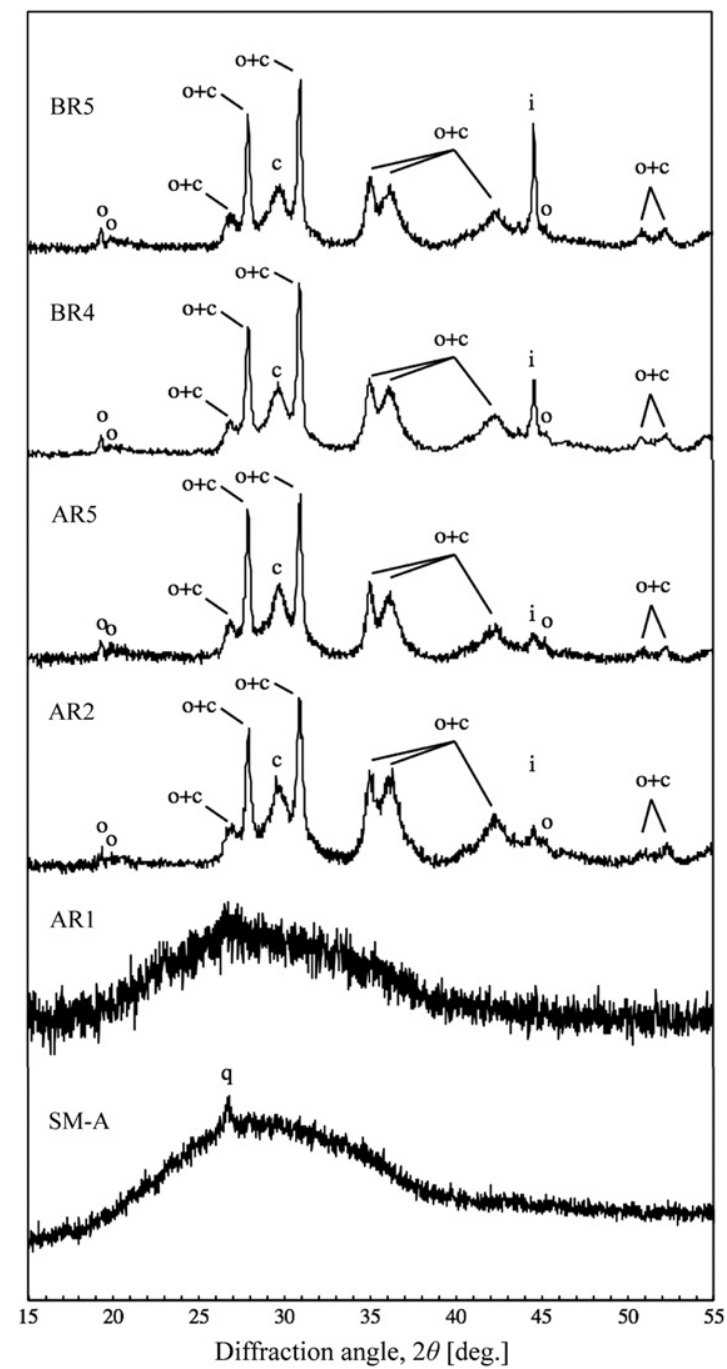

Figure 1. Powder XRD patterns of the starting material (SM-A) and different run products (AR1, AR2, AR5, BR4, and BR5) using $\mathrm{Cu} \mathrm{K} \alpha$ radiation with a step size of 0.02 . The run conditions are shown in Table 1. o: orthopyroxene, c: clinopyroxene, i: iron, and q: quartz. Quartz in SM-A might be due to contamination from material used for cleaning an agate mortar.

a cellular structure and cracks develop radially from the center of each cell (Figure 2(a)). Bright particles are present in cracks (Figure 2(b)) and have euhedral shapes (Figure 2(c)).

Cellular structures (approximately $10 \mu \mathrm{m}$ in diameter) were also observed in cross sections of the run products that used SM-A and SM-C (e.g., Figures 3(a), (c), and (e)) except for the run product of AR1, where no crystallization occurred. In the BSE images, the cell walls (approximately $2-5 \mu \mathrm{m}$ in width) and their interiors have bright and dark contrast, respectively. The EDS analyses revealed that the walls are slightly enriched in $\mathrm{Fe}$ and $\mathrm{Si}$ while the interiors are slightly depleted relative to the starting material (Figure 4(a)). This is confirmed by line profiles of elemental abundances along $\mathrm{X}-\mathrm{Y}$ in Figure 3(a), where the $\mathrm{Mg}$ content has a maximum and Fe reaches a minimum near the cell center, while $\mathrm{Si}$ and $\mathrm{O}$ contents are almost uniform (Figure 4(b)), indicating $\mathrm{Mg} / \mathrm{Fe}$ fractionation between the two parts. The cell walls in the run product with a short duration (AR4 at $1023 \mathrm{~K}$ for $3 \mathrm{hr}$; Figure 3(a)) are clearer than in the longer duration run (AR5 at $1023 \mathrm{~K}$ for $48 \mathrm{hr}$; Figure 3(c)), indicating that homogenization of $\mathrm{Mg} / \mathrm{Fe}$ between the $\mathrm{FeO}$-rich wall and the $\mathrm{MgO}$-rich center occurred by diffusion.
Figure 4(c) shows the relation between $\mathrm{O}$ abundance and the $\mathrm{Fe} /(\mathrm{Mg}+\mathrm{Fe}+\mathrm{Si})$ ratio. In this figure, the $\mathrm{O}$ abundance obtained by EDS, $\mathrm{O}_{\mathrm{EDS}}$, is normalized by the stoichiometric $\mathrm{O}$ abundance, $\mathrm{O}_{\text {sto }}$, where $\mathrm{Mg}, \mathrm{Fe}$, and $\mathrm{Si}$ are assumed to be present as $\mathrm{MgO}, \mathrm{FeO}$, and $\mathrm{SiO}_{2}$, respectively. The normalized $\mathrm{O}$ contents of $\mathrm{O}_{\mathrm{EDS}} / \mathrm{O}_{\text {sto }}>1$ are mainly due to the presence of trivalent $\mathrm{Fe}$, although errors in the $\mathrm{O}$ analysis by EDS may be superimposed. In fact, maghemite nano-crystals were observed by TEM, as described below. It is seen from the figure that variation of the $\mathrm{Mg} / \mathrm{Fe}$ ratio in the cellular structures is mainly attributed to variation of the $\mathrm{MgO} / \mathrm{FeO}$ ratio. Bright particles observed on the surfaces (Figures 2(b), (c)) and cross sections (Figure 3) are distributed on the line between silicates and ideal metallic iron, indicating that these tiny particles are metallic iron embedded in the silicates.

Many cracks (approximately $10 \mu \mathrm{m}$ in length and $1 \mu \mathrm{m}$ in width), which developed radially from the centers of the cells, were also observed in cross sections (Figure 3). Metallic iron particles (approximately $0.5-5 \mu \mathrm{m}$ ) were present along the cracks. The grain size of iron in a longer run (AR5; Figure 3(d)) is larger than that of a shorter run (AR4; Figure 3(b)). The quantity of iron grains is higher in the run product with a more reduced starting material (e.g., CR4; Figure 3(e)) than that with a more oxidized starting material (e.g., AR4; Figure 3(a)), although both textures are similar. This can be explained by easier crystallization of metallic iron from the originally more reduced glass of SM-C, in which $\mathrm{O}_{\mathrm{EDS}} / \mathrm{O}_{\text {sto }} \sim$ 1 (Figure 4(c)) suggesting almost completely divalent Fe, than the more oxidized glass of SM-A, in which $\mathrm{O}_{\mathrm{EDS}} / \mathrm{O}_{\text {sto }}>1$ (Figure 4(c)) suggesting that part of the Fe is trivalent. In BR5, which used the powdered starting material, a cellular structure was not clearly observed and iron grains were present on the surface or along cracks (Figure 3(f)).

\subsection{TEM observation}

An ultrathin section perpendicular to the FeO-rich walls of the cellular structure was extracted by FIB (Figure 5(a)) and observed by TEM. The following three components can be observed in bright-field images (Figure 5(b)): (1) dark grains approximately $80 \mathrm{~nm}$ in size (arrows), (2) domains with banded structures (white circles), and (3) domains with relatively bright contrast (dashed black circles). Lattice fringes in the dark grains (Figure 5(c)) are compatible with the lattice spacing of maghemite $\left(\begin{array}{lll}1 & 0 & 0\end{array}\right)$. A selected area electron diffraction pattern (Figure $5(\mathrm{~d})$ ) of the dark grain can be explained as maghemite $\left(\gamma-\mathrm{Fe}_{2} \mathrm{O}_{3}\right)$. The banded structures correspond to clinopyroxene crystals with polysynthetic twining. The twin boundaries are almost parallel to one another and the elongated domains developed from the center of the cellular structure to the wall (Figure 5(b)). The bright domains are likely orthopyroxene because the XRD pattern indicated that orthopyroxene is a major component of the run product (Figure 1).

\section{DISCUSSION}

\subsection{Possible Formation Process for the Run Product Textures}

The characteristic structures in the run products (cellular structures with maghemite nano-grains in elongated pyroxene crystals and metallic iron grains on the surface and along cracks) and chemical heterogeneities, such as FeO-rich cell walls (Figures 4(a), (b)), can be explained by following processes. (1) Pyroxene crystallized from the glass as spherulites by rapid 

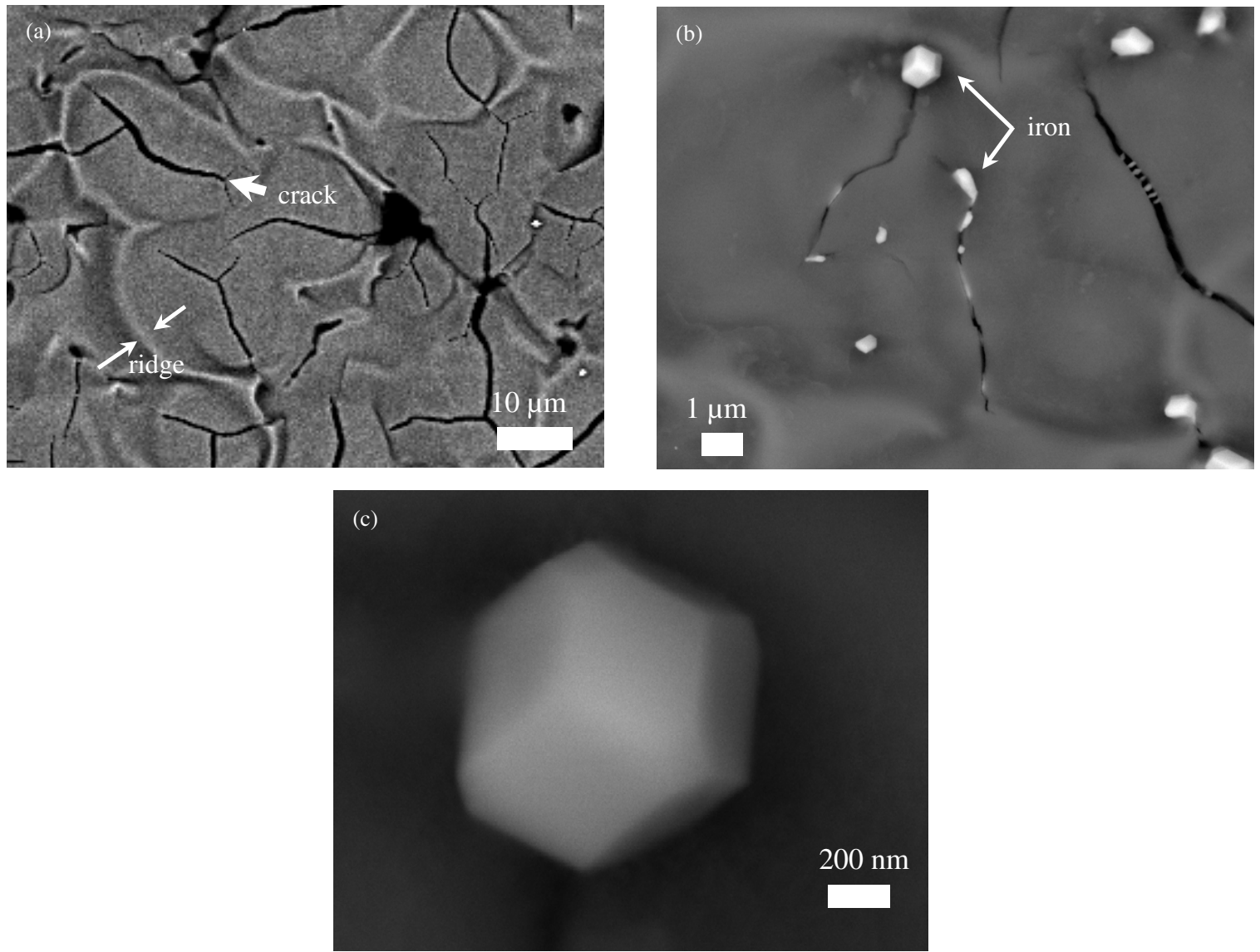

Figure 2. BSE surface images of AR4 (1023 K, $3 \mathrm{hr}$ ) obtained using FE-SEM showing several cracks and ridges with bright particles. (a) Ridges forming a cellular structure and cracks developing radially from the center of each cell. (b) Bright particles (metallic iron) present in cracks. (c) A bright particle (metallic iron) with a euhedral shape.

growth taking $\mathrm{Fe}^{2+}$ in and maghemite nano-grains crystallized by taking a small amount of $\mathrm{Fe}^{3+}$ in the glass between the pyroxene grains (Figure 6(a)), although we did not know which of them crystalized primarily without an observation of the growth center. (2) Cracks formed due to a volume change caused by pyroxene crystallization. (3) Iron grains formed on the surface or along cracks by reaction with the surrounding reducing gas (Figure 6(b)). (4) Cellular structures formed by encountering different spherulites. The FeO-rich cell walls were created by fractional crystallization of relatively $\mathrm{MgO}$-rich pyroxene.

\subsection{Diffusion Process and Formation of Metallic Fe}

Crystallization of iron grains on the sample surfaces and along cracks and that of maghemite nano-grains away from the surfaces and cracks indicate that reduction of Fe occurred only at the glass-gas interfaces but not inside the glass. The growth of iron grains on the solid surface should be advance by diffusion of hydrogen from the interface towards the glass interior and/or diffusion of iron and oxygen from the glass interior to the interface. $\mathrm{Fe}$ or $\mathrm{O}$ diffusion should control the growth rate because both $\mathrm{Fe}$ and $\mathrm{O}$ diffusivities are much slower than $\mathrm{H}$ diffusion. For example, diffusion coefficients of $\mathrm{H}, \mathrm{Fe}$, and $\mathrm{O}$ atoms, $D(\mathrm{H}), D\left(\mathrm{Fe}^{2+}\right)$, and $D(\mathrm{O})$, are estimated to be approximately $4 \times 10^{-10}, 2 \times 10^{-16}$, and $4 \times 10^{-17} \mathrm{~m}^{2} \mathrm{~s}^{-1}$, respectively, at $1023 \mathrm{~K}$ by extrapolating $D(\mathrm{H})$ data for a silica melt (Shang et al. 2009), and data from basalt glasses for
Table 2

Diffusion Coefficients and the Diffusion Distances

\begin{tabular}{lccl}
\hline \hline Elements & $D\left(\mathrm{~m}^{2} \mathrm{~s}^{-1}\right]$ & $X^{*}(\mu \mathrm{m})$ & References \\
& $(T=1023 \mathrm{~K})$ & $(T=1023 \mathrm{~K}, t=3 \mathrm{hr})$ & \\
\hline $\mathrm{H}$ & $4 \times 10^{-10}$ & $2 \times 10^{3}$ & Silica melt [1] \\
$\mathrm{O}$ & $4 \times 10^{-17}$ & 1 & Basalt melt [2, 3] \\
$\mathrm{Fe}^{2+}$ & $2 \times 10^{-16}$ & 2 & Basalt melt [4] \\
\hline
\end{tabular}

Notes.

${ }^{*} X=[D t]^{1 / 2}$

[1] Shang et al. (2009), [2] Muehlenbachs \& Kushiro (1974), [3] Canil \& Muehlenbachs (1990) and [4] Lowry et al. (1982).

$D(\mathrm{Fe})$ (Lowry et al. 1982) and for $D(\mathrm{O})$ (Muehlenbachs \& Kushiro 1974; Canil \& Muehlenbachs 1990; Table 2). Because $D(\mathrm{Fe})>D(\mathrm{O})$, O diffusion should control the growth rate. The characteristic diffusion distance of oxygen, $X(\mathrm{O}) \sim[D(\mathrm{O}) t]^{1 / 2}$ (approximately $1 \mu \mathrm{m}$ at $1023 \mathrm{~K}$ for $t=3 \mathrm{hr}$ ), is consistent with limited metallic iron formation only at the glass-gas interface and also consistent with maghemite crystallization, which occurred away from the interface in the $\mathrm{Fe}^{3+}$-bearing glass.

Considering homogeneous distributions of $\mathrm{O}^{2-}$ and $\mathrm{Fe}^{2+}$, and the absence of $\mathrm{Fe}^{0+}$ and ignoring $\mathrm{Fe}^{3+}$ in the glass at the initial state (Figure 7(a)), the reducing reaction

$$
\mathrm{Fe}^{2+}(\mathrm{gl})+\mathrm{O}^{2-}(\mathrm{gl})+\mathrm{H}_{2}(\mathrm{gas}) \rightarrow \mathrm{Fe}^{0+}(\mathrm{gl})+\mathrm{H}_{2} \mathrm{O}(\mathrm{gas})
$$



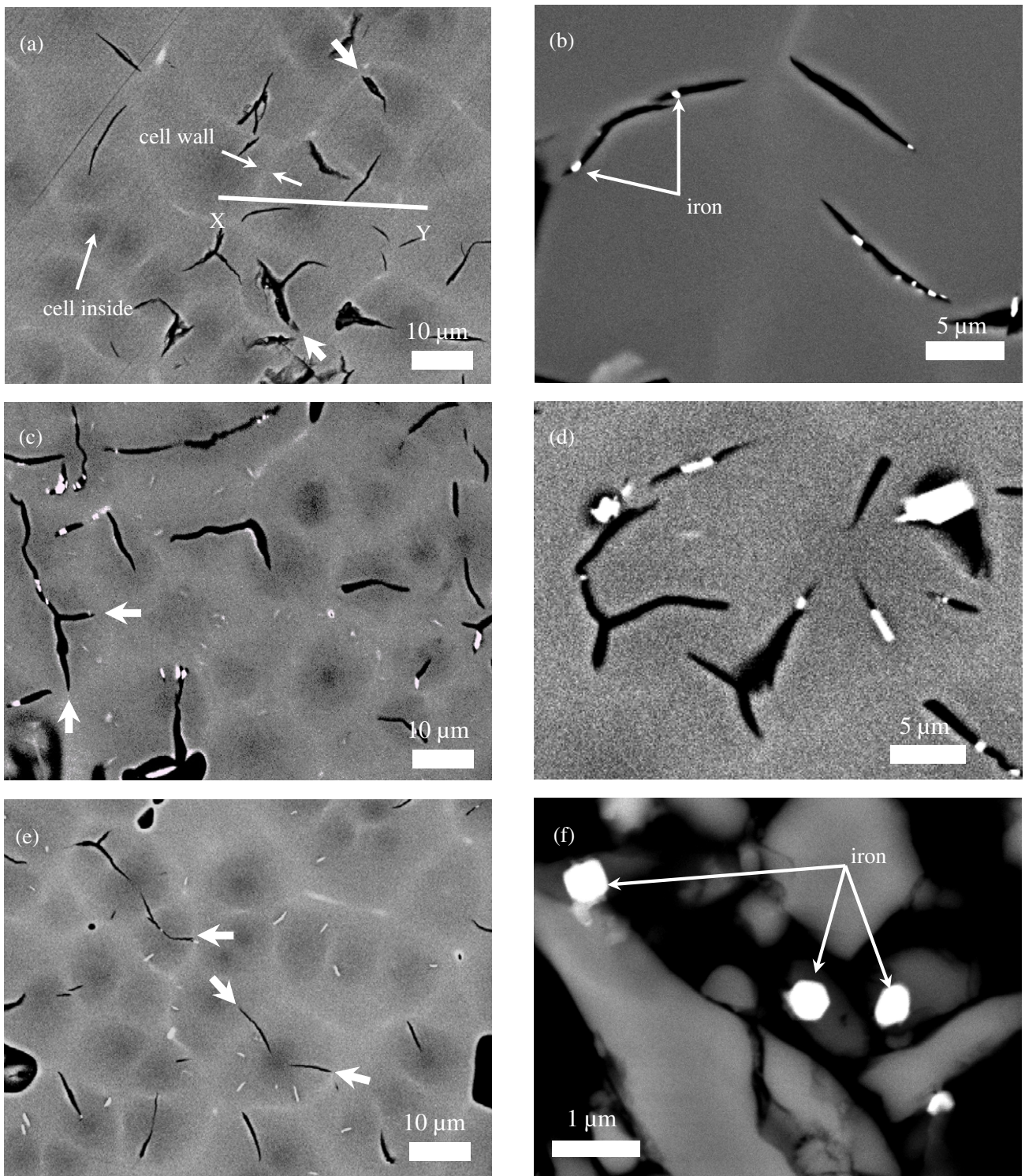

Figure 3. Cross-sectional BSE images of run products obtained by FE-SEM. (a) and (b) AR4 (1023 K, 3 hr). (c) and (d) AR5 (1023 K, 48 hr). (e) CR4 (1023 K, 3 hr). (f) BR5 (1023 K, $48 \mathrm{hr}$ ). Cellular structures are observed in run products using the starting material of SM-A (a-d) and SM-C (e). The cell walls (approximately $2-5 \mu \mathrm{m}$ in width) and insides have bright and dark contrasts, respectively. Cracks were observed perpendicular to the cell walls (thick arrows). Bright grains are identified as metallic iron. Line profiles of elements from $\mathrm{X}$ to $\mathrm{Y}$ in (a) are shown in Figure 4(b).

where (gl) and (gas) denote glass and gas phases, respectively, should occur at the interface, and this reaction increases the $\mathrm{Fe}^{0+}$ concentration in the glass from the surface (Figure 7(b)). $\mathrm{As}_{2}$ (or $\mathrm{H}$ ) molecules diffuse into the glass from the interface, reduction of $\mathrm{Fe}^{2+}$ also occurs in the interior of the glass:

$$
\mathrm{Fe}^{2+}(\mathrm{gl})+\mathrm{O}^{2-}(\mathrm{gl})+\mathrm{H}_{2}(\mathrm{gl}) \rightarrow \mathrm{Fe}^{0+}(\mathrm{gl})+\mathrm{H}_{2} \mathrm{O}(\mathrm{gl}) .
$$

The amount of $\mathrm{Fe}^{0+}(\mathrm{gl})$ produced by reaction (2) is smaller than that produced by reaction (1) because the activity of $\mathrm{H}_{2}$ at the interface is larger than that in the interior. Therefore, the concentration profiles of the species in the glass are not quantitatively different from those in Figure 7(b). Because a nucleation frequency of metallic iron reaches the maximum where the $\mathrm{Fe}^{0+}$ concentration is the highest, the metallic iron grains crystallize on the surface. In addition, heterogeneous nucleation generally occurs on the surface rather than in the interior of the silicate glass by homogeneous nucleation, and thus metallic iron more easily grow towards free space on the surface. In fact, Uesugi et al. (2008) estimated the stabilities of surface energies between silicate and metallic iron, and showed that the metal grains locating on the silicate surface are more stable than those embedding in a silicate. The above discussion indicates that the nucleation of metal grains occur on the surface by the following overall reaction:

$$
\mathrm{Fe}^{2+}(\mathrm{gl})+\mathrm{O}^{2-}(\mathrm{gl})+\mathrm{H}_{2}(\text { gas }) \rightarrow \mathrm{Fe}^{0+}(\mathrm{sol})+\mathrm{H}_{2} \mathrm{O}(\text { gas }),
$$

where (sol) denotes solid.

The diffusion distance, $X(\mathrm{O})$ or $X\left(\mathrm{Fe}^{2+}\right)$ (approximately $2 \mu \mathrm{m}$ at $1023 \mathrm{~K}$ for $t=3 \mathrm{hr}$ ), can be regarded as the area from which $\mathrm{Fe}^{2+}$ are supplied for metallic iron growth. If the width of the starting glass is smaller (or thinner) than the size of the diffusion area, the size of metallic grains that form at the grain surfaces should be smaller. In other words, surface to volume $(S / V)$ ratios of the starting materials should be related to the iron size. In fact, 
(a)

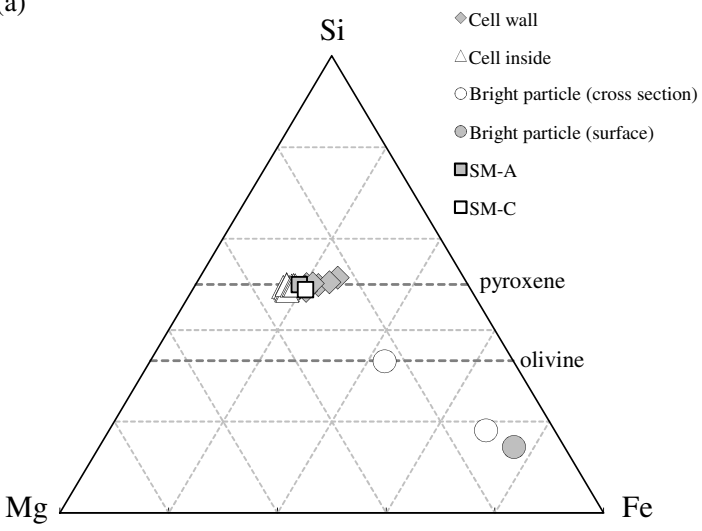

(b)

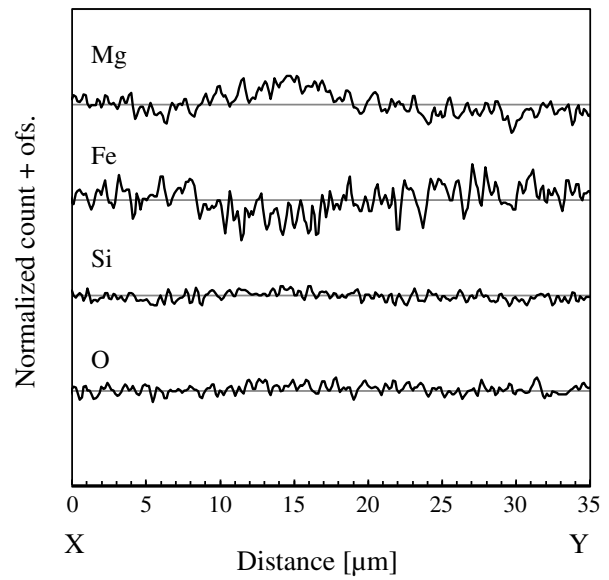

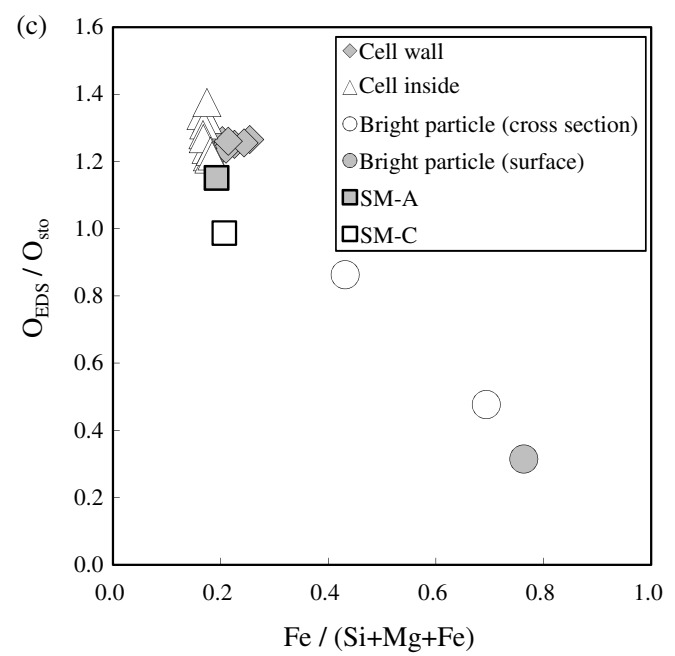

Figure 4. FE-SEM/EDS analyses of AR4 (1023 K, $3 \mathrm{hr}$ ). (a) Chemical compositions plotted in a ternary diagram of the $\mathrm{Si}-\mathrm{Mg}-\mathrm{Fe}$ system (in atomic ratios). (b) Mg, $\mathrm{Si}, \mathrm{Fe}$ and $\mathrm{O}$ profile concentrations along $\mathrm{X}-\mathrm{Y}$ in Figure 3(a) (arbitrary scale). (c) $\mathrm{O}_{\mathrm{EDS}} / \mathrm{O}_{\text {sto }}$ plotted against $\mathrm{Fe} /\left(\mathrm{Si}+\mathrm{Mg}+\mathrm{Fe}\right.$ ) (in atomic ratios). $\mathrm{O}_{\mathrm{EDS}}$ is the $\mathrm{O}$ abundance measured by EDS and $\mathrm{O}_{\text {sto }}$ is the stoichiometric $\mathrm{O}$ abundance calculated from the composition of each oxide by assuming $\mathrm{Mg}$, Fe and $\mathrm{Si}$ are present as $\mathrm{MgO}, \mathrm{FeO}$ and $\mathrm{SiO}_{2}$, respectively. The chemical compositions of starting materials A (SM-A) and C (SM-C) are also plotted in (a) and (c).

the typical size of metallic Fe grains is approximately $500 \mathrm{~nm}$ in BR5 using a starting glass powder with a size of $1-30 \mu \mathrm{m}$ (Figure 3(f)), while Fe grains are in the size range $0.5-5 \mu \mathrm{m}$ in AR5 using a starting glass particles size approximately $2 \mathrm{~mm}$ (Figures 2, 3(b) and (d)).

The experimental results of Davoisne et al. (2006) can also be explained by the above discussion. In their experiments, the reducing reaction

$$
\mathrm{Fe}^{2+}(\mathrm{gl})+\mathrm{O}^{2-}(\mathrm{gl})+\mathrm{C}(\mathrm{g}) \rightarrow \mathrm{Fe}^{0+}(\mathrm{gl})+\mathrm{CO}(\mathrm{g})
$$

where $\mathrm{C}(\mathrm{g})$ denotes unidentified $\mathrm{C}$ species in the gas phase produced from vacuum oil, should mainly occur on the surface. Considering time development profiles of the concentrations of $\mathrm{C}, \mathrm{CO}, \mathrm{O}^{2+}, \mathrm{Fe}^{2+}$, and $\mathrm{Fe}^{0+}$ from an initial state in analogy with Figure 7, the $\mathrm{Fe}^{0+}$ content increases from the surface of the glass. This means that the metallic iron should also start to form on the surface of the silicate film although the nucleation sites of metallic grains have not been observed in the experiments. Some metal grains might nucleate at the interfaced between the silicate film and diamond substrate by reducing reaction with diamond. The size of metallic grains in the previous experiments $(2-50 \mathrm{~nm})$ should be limited by the thickness of the film (50-100 nm), or reflects the large $S / V$ ratios of the starting materials. In contrast, the present experiments used relatively large glass particles ( $\sim 1 \mathrm{~mm}$ cubes) with the small $S / V$ ratios.

\subsection{Application to Metallic Fe in GEMS}

The present experiments showed that metallic iron grains form on the solid surface when $\mathrm{FeO}$-bearing amorphous silicates become reduced. This type of iron grain formation also occurs on a smaller scale than the present experiments. If metallic iron grains in natural GEMS formed by the reduction of FeO-bearing amorphous silicates as Davoisne et al. (2006) proposed, then metallic nano-grains should form only on the solid surface of GEMS (Figure 8(a)). It should be noted that silicates in GEMS grains are mostly amorphous and only 10\%-20\% of GEMS grains have crystals (Bradley \& Dai 2004), while pyroxene formed together with metallic iron in the present experiments. Formation of metallic iron by reduction without silicate crystallization might occur at lower temperatures over longer timescales than those in the present experiments. Comparing the $f_{\mathrm{O} 2}$ condition between in the present experiment $\left(\sim 10^{-23} \mathrm{~atm}\right)$ and in the solar nebula $\left(\sim 10^{-25} \mathrm{~atm}\right.$ at $1000 \mathrm{~K}$; Williams 1971$)$, the solar nebula was much more reduced. In the high-reducing conditions, the nucleation frequency of metallic iron was higher and Fe-metal grains formed more easily. Thus, iron-metal formation will be 

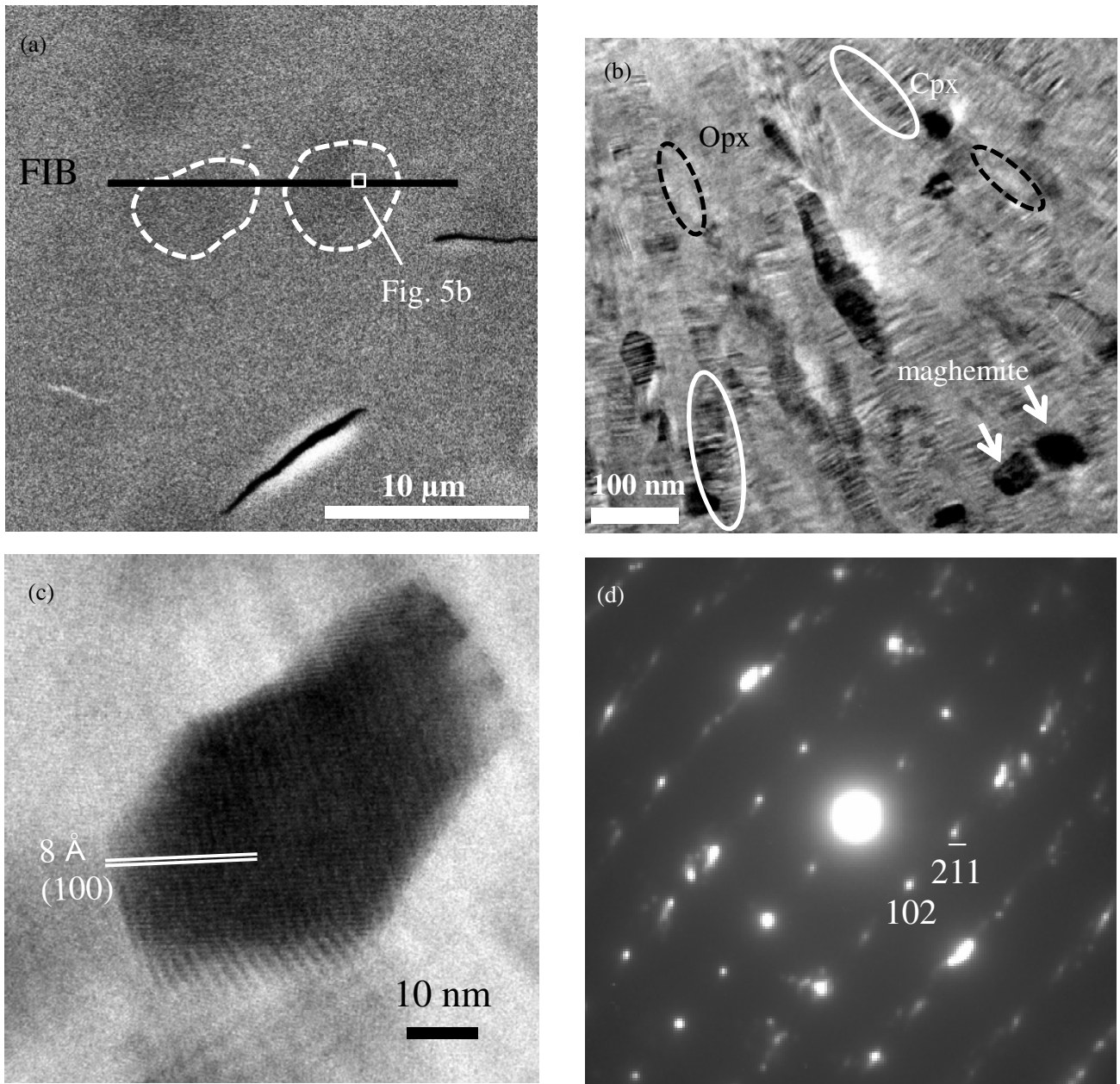

Figure 5. (a) A cross-sectional BSE image of AR5 (1023 K, 48 hr). An ultrathin section was prepared using a FIB along the black line. Regions surrounded by dashed white lines indicate the interior regions of the cellular structure. (b) and (c) TEM micrographs (bright-field) of the ultrathin section. The observed area in (b) is indicated in (a). Clinopyroxene (Cpx), orthopyroxene (Opx), and maghemite were observed, as indicated by white circles, dashed black circles, and white arrows, respectively in (b). The lattice spacing of $8 \AA$ in (c) is consistent with maghemite $\left(\begin{array}{lll}1 & 0 & 0\end{array}\right)$. (d) A selected-area electron diffraction pattern of the crystal in (c) corresponding to the $\langle 23-1\rangle$ zone axis of maghemite.
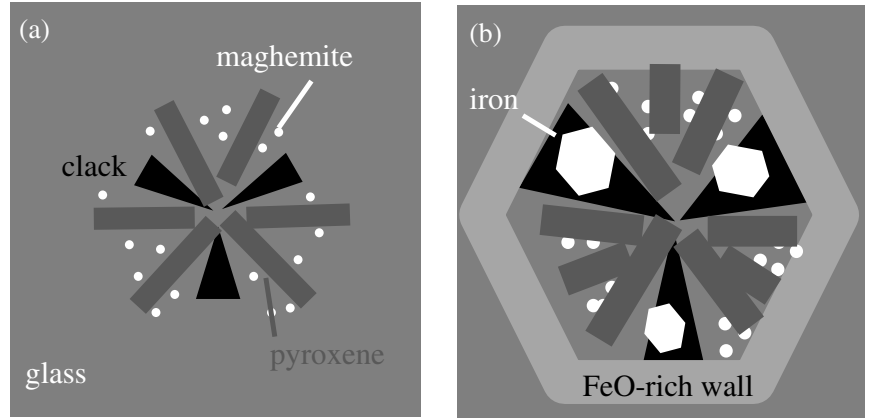

Figure 6. Schematic illustrations of a formation model for the cellular structures and metallic iron particles observed in the run product cross-sections (a) Pyroxene (dark gray bands) crystallizes outward from the center of the glass as a spherulite almost together with crystallization of maghemite nano-grains (white dots) between the pyroxene crystals. Cracks (black) are formed by a volume change due to pyroxene crystallization. (b) Metallic iron grains (white hexagons) crystalize along cracks through reaction with reducing gas, which comes from the exterior along the cracks. FeO-rich cell walls (light gray) also form as a result of pyroxene spherulite crystallization.

possible at low temperatures where no crystalline silicates form from amorphous silicates. The grain size of metallic iron should be small due to the high nucleation frequency. However, even in this case, iron grains formed by reduction should occur on the surface, as suggested by the present experiments (Figure 8(a)).

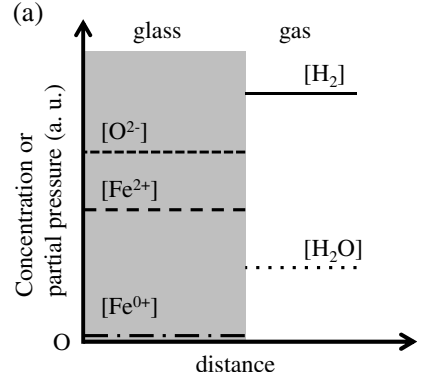

(b)

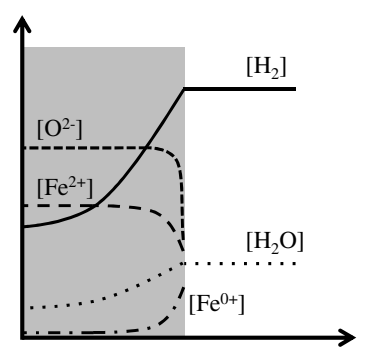

Figure 7. Schematic illustrations of distribution of diffusing species in glass near the glass-gas interface. (a) Initial state. (b) After heating. Partial pressures of gas species are also shown. The units for the concentrations of diffusing species and the partial pressures are arbitrary but are normalized by the equilibrium values at the interface. The partial pressure of $\mathrm{O}_{2}, p\left(\mathrm{O}_{2}\right)$, is not drawn because of the negligibly small value $\left[p\left(\mathrm{H}_{2}\right)>p\left(\mathrm{H}_{2} \mathrm{O}\right) \gg p\left(\mathrm{O}_{2}\right)\right]$ by considering the reaction $\mathrm{H}_{2}(\mathrm{~g})+1 / 2 \mathrm{O}_{2}(\mathrm{~g})=\mathrm{H}_{2} \mathrm{O}(\mathrm{g})$. Other species such as $\mathrm{Mg}^{2+}$ or $\mathrm{Si}^{4+}$ are not shown for simplicity.

In contrast, TEM observations of natural GEMS show that metallic grains are uniformly embedded in an amorphous silicate matrix, as schematically illustrated in Figure 8(b) (e.g., Keller \& Messenger 2011). This strongly suggests that metallic grains in GEMS did not form by reduction of FeO-bearing silicates but probably formed by irradiation in the interstellar medium 
(a)

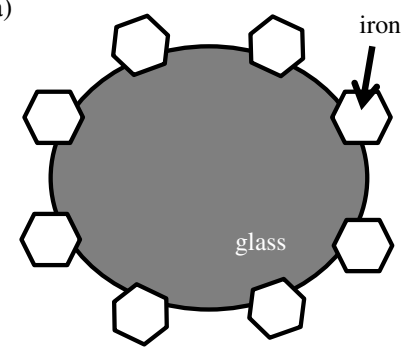

(b)

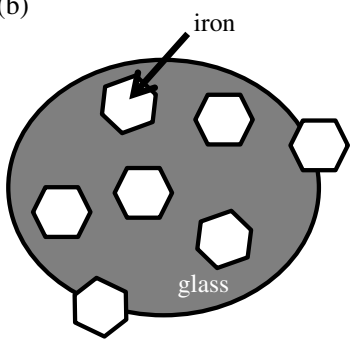

Figure 8. Schematic illustrations of textural relation between metallic iron grains and glass for (a) reduction products and (b) a typical natural GEMS. Metallic iron and iron sulfide grains in GEMS are located inside the glass, while the present experiments indicate that metallic iron crystallizes on the glass surface during heating in a reducing atmosphere.

(Bradley \& Dai 2004; Bradley 2013) or by condensation from a gas together with amorphous silicates during GEMS formation (Keller \& Messenger 2011, 2013).

We thank Dr. N. Shimobayashi and Mr. N. Souma of Kyoto University for assistance with FIB and TEM techniques, and Dr. A. Gucsik of Tohoku University for helpful discussions and proofreading. We are also grateful to G. Libourel for his careful and constructive review, which significantly improved this article. J.M. is supported by a Research Fellowship for Young Scientists from the Japan Society for the Promotion of Science (No. 25-1031).

\section{REFERENCES}

Bradley, J. P. 1988, GeCoA, 52, 889

Bradley, J. P. 1994a, Sci, 265, 925

Bradley, J. P. 1994b, GeCoA, 58, 2123

Bradley, J. P. 2013, GeCoA, 107, 336

Bradley, J. P., \& Brownlee, D. E. 1986, Sci, 231, 1542

Bradley, J. P., \& Dai, Z. 2004, ApJ, 617, 650

Bradley, J. P., \& Ireland, T. R. 1996, in ASP Conf. Ser. 104, Phys. Chem. and Dynamics of Interplanetary Dust, ed. B. A. S. Gustafson \& M. S. Hanner (Gainesville, FL: ASP), 275

Canil, D., \& Muehlenbachs, K. 1990, GeCoA, 54, 2947

Davoisne, C., Djouadi, Z., Leroux, H., et al. 2006, A\&A, 448, L1

Dobrică, E., Engrand, C., Leroux, H., et al. 2012, GeCoA, 76, 68

Duprat, J., Dobrică, E., Engrand, C., et al. 2010, Sci, 328, 742

Flynn, G. J. 1989, Icar, 77, 287

Huebner, J. S. 1980, in Pyroxenes, ed. C. T. Prewitt (Washington, DC: Mineralogical Society of America), 213

Keller, L. P., \& Messenger, S. 2011, GeCoA, 75, 5336

Keller, L. P., \& Messenger, S. 2013, GeCoA, 107, 341

Leroux, H., Cuvillier, P., Zanda, B., et al. 2013, Lunar Planet. Sci. Conf. 44 Abstract no. 1528

Lowry, R. K., Henderson, P., \& Nolan, J. 1982, Contrib. Mineral Petrol., 80,245

Matsuno, J., Tsuchiyama, A., Noda, J., et al. 2014, Lunar Planet. Sci. Conf. 45 , Abstract no. 1335

Muehlenbachs, K., \& Kushiro, I. 1974, Carnegie Inst Wash Yearbook, 73, 232

Noguchi, T., Ohashi, N., Nishida, S., et al. 2008, Annual Meeting of the Meteoritical Society, 71, Abstract no. 5129

Noguchi, T., Ohashi, N., Tsujimoto, S., et al. 2013, Lunar Planet. Sci. Conf. 44, Abstract no. 1380

Shang, L., Chou, I. M., Lu, W., et al. 2009, GeCoA, 73, 5435

Uesugi, M., Sekiya, M., \& Nakamura, T. 2008, M\&PS, 43, 717

Williams, R. J. 1971, GeCoA, 35, 407 